\title{
Mitigation of Climate Change through Conservation Agriculture
}

\author{
Zelalem Addis \\ South Agricultural Research Institute Bonga Agricultural Research Center \\ P.O.Box101, Bonga \\ Shewatsehay Asalf \\ South Agricultural Research Institute Hwassa Agricultural Research Center \\ P.O.Box 6, Hawassa
}

\begin{abstract}
Current and future global environmental change, in combination with population growth and increase in consumption per capital, poses a great threat to global food security. In addition, it is predicted that up to $25 \%$ of world food production may be lost during the $21^{\text {st }}$ century due to climate change, water scarcity, invasive pests and land degradation.Smallholders in Ethiopia face widespread problems related to inappropriate cultivation, overgrazing and deforestation, resulting in soil erosion and soil fertility decline, water scarcity, lack of pasture and livestock feed, and fuel wood crisis. This cycles requiring urgent action and different approaches in the dry lands and highland areas adapting to climate change through land and Water management. Increasing weather variability and climate change are contributing to land and natural resource degradation by exposing soils to extreme conditions and straining the capacity of existing land management practices to maintain resource quality. Results include degradation of vegetation cover and loss of biodiversity, soil erosion, depletion of organic matter, reduced rainwater infiltration and water holding capacity of the soil and loss of productivity and effects on wider ecological functions. So that by considering the climate change as national and global condition it is a time to taking action through different alternatives. Among the options conservation agriculture system is one of non-substitutable option among others due to its smartness with climate change by improving soil fertility, water management and food security.
\end{abstract}

DOI: $10.7176 / \mathrm{JNSR} / 12-1-03$

Publication date: January $31^{\text {st }} 2021$

\section{INTRODUCTION}

Current and future global environmental change, in combination with population growth and increase in consumption per capital, poses a great threat to global food security. Estimation states that if the current trends in diet and food waste continue, food production will increase by $60 \%$ by 2050 from $2005 / 2007$ to feed the well above 9 billion people that is expected (McKenzie and Williams, 2015). In addition, it is predicted that up to 25\% of world food production may be lost during the $21^{\text {st }}$ century due to climate change, water scarcity, invasive pests and land degradation (UNEP, 2009). Already now, climate change constitutes a serious challenge to food production: The net reduction of global yields of maize and wheat since 1980 have been estimated to be about $3.8 \%$ and 5.5\% respectively, relative to what would have been achieved without the global warming (Lobell et al., 2011). Despite uncertainties on the directions and amplitude of climate changes, there is significant information and scientific evidence that indicates an increase in average temperature and in climate variability in the semi-arid tropics, with subsequent increases in the occurrence of droughts, floods and heat waves that affect people, their crops and their livestock. Predictions of future climates for the countries of Eastern Africa vary, with high altitude areas of Ethiopia potentially benefiting from warming temperatures. However, without adequate adaptation measures, most of the region is likely to be deleteriously affected by rising temperatures leading to increasing rates of evaporation and transpiration, changes in the timing and reliability of rains, and, in many areas, an increase in the intensity of rainfall events and in the frequency and duration of droughts. Some of these changes are already being experienced across the region; others are predicted in the near future (FAO, 2010)

Smallholders in Ethiopia generally face widespread problems related to inappropriate cultivation, overgrazing and deforestation, resulting in soil erosion and soil fertility decline, water scarcity, lack of pasture and livestock feed, and fuel wood crisis. This vicious cycle of "poverty, food insecurity and natural resources degradation" is driven by population growth but is being exacerbated by increasing weather variability and climate change, requiring urgent action and different approaches in the drylands and highland areas (adapting to climate change through land and Water management in eastern Africa Food and agriculture organization of the united nations. Increasing weather variability and climate change are contributing to land and natural resource degradation by exposing soils to extreme conditions and straining the capacity of existing land management practices to maintain resource quality. Results include degradation of vegetation cover and loss of biodiversity, soil erosion, depletion of organic matter, reduced rainwater infiltration and water holding capacity of the soil and loss of productivity and effects on wider ecological functions 
The increase in food production must also be obtained through environmentally sustainable agriculture. Ongoing soil and water degradation and the loss of biodiversity and ecosystem services in agricultural landscapes, constitute big challenges for future food systems .To meet the world's future food security needs, agriculture's environmental footprint must shrink dramatically, and ecosystem services must be restored . From the 1950s, global fertilizer use has increased by $500 \%$, and pesticide use has increased with about $850 \%$ (McKenzie and Williams, 2015). Due to the high environmental costs of inputs and high economic costs for the farmers, there is a need to find solutions for agriculture intensification that are also input-sensitive.

The International Panel on Climate Change (IPCC) Fifth Assessment Report WGII found that recent reports from the Famine Early Warning Systems Network (FEWS NET) indicate that there has been an increase in seasonal mean temperature in many areas of Ethiopia (IPCC, 2014). According to the UNDP climate change country profiles, the average annual temperature in Ethiopia increased by $1.3 \mathrm{c}^{\circ}$ between 1960 and 2006 Daily temperature observations also show an increase in the average number of 'hot' days and 'hot' nights per year. (Ethiopia climate action report for 2015, Climate Policy | Irish Aid | September, 2016). Ethiopia submitted to the UNFCCC approximately 70 specific actions or projects as its Nationally Appropriate Mitigation Action (NAMA) up to the year 2020. These actions include projects in: renewable energy from hydro, wind, solar, geothermal and biofuel sources; railway projects; agriculture including soil and agro-forestry measures; forestry; and waste management. Ethiopia seeks financial and technical support for these actions (Ethiopia climate action report for 2015, Climate Policy | Irish Aid | September, 2016). So-called Climate-smart agriculture (CSA) has been promoted as a solution to overcome the challenge of how to increase food production and food security in an environmentally sustainable way. CSA is an umbrella term for different agricultural methods that are assumed to have a "triple win"-effect: Increasing productivity, mitigating $\mathrm{CO}_{2}$-emissions and increasing climate adaptation (FAO, 2013). CSA has received an increasing amount of attention during recent years, and this new buzzword has now gained a strong position within the global development discourse. Its approach of transforming agricultural practices and systems holds a promise of ensuring food security in face of the dual challenges of climate change and resource scarcity (Lipper et al., 2014). As a consequence, agriculture and its linkages to climate change and adaptation is now the focus of attention by a wide part of the international community, with actors such as the World Bank and the UN Food and Agriculture Organization (FAO) leading the way.

\section{Mitigation of climate change through conservation agriculture \\ 2.1. Climate-smart agriculture (CSA)}

The concept of climate-smart agriculture (CSA) has been defined as agricultural practices with the triple wins of sustainably increasing productivity, enhancing resilience and reducing greenhouse gas emissions. The term CSA was first presented at the First Global Conference on Agriculture, Food Security and Climate Change in The Hague in 2010. The Conference was organized by the Dutch Ministry of Economic Affairs, Agriculture and Innovation in close cooperation with Ethiopia, Viet Nam, Mexico, New Zealand, Norway, the World Bank and the UN Food and Agriculture Organization (FAO, 2010). The outcome of the conference was a Chair's summary, containing a Roadmap for Action. The summary stated that: "The Conference has showcased issues and shared knowledge on replicable good practices in climate resilient, low-emissions agriculture, livestock, fisheries, forestry and watershed management and demonstrated the potential for scaling up in a sustainable manner; and used innovative approaches to bring together private and public sector finance for investments in climate-smart agricultural systems" (FAO, 2010).

CSA includes proven practical techniques such as mulching (crop residue cover), intercropping, crop rotation, integrated crop-livestock management, terracing, agroforestry, improved grazing and improved water management. CSA also involves innovative practices such as improved weather forecasting, early-warning systems and climaterisk insurance. A pronounced aim is to get existing technologies off the shelf and into the hands of farmers, as well as to develop new technologies such as drought-tolerant or flood-tolerant crops to meet the demands of the changing climate (FAO, 2016).

Although CSA as a concept can be said to have successfully united the global communities on agriculture, climate and development for a common purpose, it has also been criticised. argue that despite the fact that only practices that encompass all three of the CSA dimensions (increased productivity, climate mitigation and adaptation) are able to earn the climate-smart label, the interaction between the three dimensions of CSA are so poorly understood that almost any agricultural method that shows marginal improvement in one way or another can be considered climate-smart. According to the definition, it is possible to imagine that agricultural methods which may have adverse impacts on the local environment can still be labeled climate-smart as long as the three dimensions are ensured. This is because considerations in regards to biodiversity, eco-system services, soil health, and resource use and management are not included in the definition (Neufeldt et al., 2013)

\subsection{Climate change policy and agriculture}

Under the late Prime Minister Meles Zenawi, Ethiopia was at the forefront of Africa's climate policy development. 
Established under his leadership, the country embarked on a Climate Resilient Green Economy (CRGE) initiative, a key plank in the wider and even more ambitious Growth and Transformation Plan, (GTP). This plan seeks to enable an economic transformation to middle income status by 2025. The CRGE is receiving substantial support from UKAid, South Korea, Japan and the UNDP. Core aspects of the GTP are capacity development and improving access to markets, including supporting co-operatives and agribusinesses. It also seeks to improve rural infrastructure, including provision of roads, irrigation schemes and market facilities such as grain stores and refrigeration (DFID, 2011).Core investment approaches are being led by the Agricultural Transformation Agency (ATA) set up under the Ministry of Agriculture with funding from the BMGF. ATA is responsible for developing policy approaches in support of GTP and envisages a shift from lower- to higher value agricultural production, anticipating that such a shift will be central to future national economic success. The Agricultural Growth Programmed (AGP) set up across four regions with a budget of $\$ 280 \mathrm{~m}$ aims to increase productivity and access to markets, and includes a focus on increased engagement by women and youth. A major focus on stronger farmer organizations and service providers, better rural infrastructure, including more efficient value chains, soil and water conservation, as well as programmed monitoring and evaluation seeks to reduce exposure to environmental risk and to strengthen resilience to livestock and crop losses during dry periods. The ambition level is high and the intent is to accelerate change. According to Conway and Schipper (2011) climate change scenarios specific to Ethiopia have projected mean annual temperature across the country increasing by between 1.4 and $2.9^{\circ} \mathrm{C}$ by the 2050s. Projections regarding rainfall are less certain, but suggest the possibility of more frequent and intense patterns of extreme weather.

Implications for the agricultural sector are not immediately conclusive, particularly because of the major uncertainty surrounding specific seasonal and monthly shifts in different regions of the country, which can be critical for smallholder productivity and food security.at the national level, Much of this impact route will be effects in the agricultural sector. along-term trend analysis (mid-1970s to 2000s) concluded amongst other things, that continued rapid population growth and the expansion of farming and pastoralism under a drier, warmer climate regime could dramatically increase the number of at-risk people in Ethiopia during the next 20 years, although many areas of Ethiopia would maintain moist climate conditions, and agricultural development in these areas could help offset rainfall declines and reduced production in other areas

Changing temperature regimes will affect not only growing seasons, but also the prevalence of natural pests that attack key cash crops. These impacts are anticipated to have very significant implications for the livelihoods of the poorest farmers. Some reports suggest that there is already expansion in crop diseases, including those affecting the critical food staple enset (or false banana) in southern Ethiopia. Crop weather insurance is being considered one important mechanism to encourage farmers to 'invest more', but will only work in conjunction with other inputs that help in mitigating environmental asset degradation. It is argued, for instance, that forest cover has declined from $30 \%$ to around $3 \%$ in the past 30 years.

\subsection{Conservation Agriculture Impacts}

\subsubsection{Greenhouse gas balances}

This section explores the extent to which current CA projects are reducing greenhouse gas (GHG) emissions or sequestering significant net amounts of carbon. To do so, it reviews evidence from the published literature on the contribution of different agro ecosystem components to GHG mitigation. It then evaluates the practice of CA in sub-Saharan Africa in light of these data. According to the Intergovernmental Panel on Climate Change (IPCC), agriculture, deforestation, and land-use change together account for about $31 \%$ of total global anthropogenic GHG emissions. In Africa, land use change is a disproportionately important contributor to GHG emissions, accounting for 48\% of the continent's emissions from 2000-2005 (Canadell et al., 2009). Put another way, Africa accounted for just $2.5 \%$ of the world's $\mathrm{CO} 2$ emissions from fossil fuel combustion, but $17 \%$ of all global $\mathrm{CO} 2$ emissions from land use change. At the same time, carbon in African topsoil is being released to the atmosphere as the many of the continent's croplands, rangelands, and forests become progressively more degraded. Looking to the future, Africa is projected to have the highest growth in agricultural GHG emissions, alongside the Middle East, largely due to agricultural intensification and expansion (Smith et al., 2007).

Just as agriculture and land use change has significant potential to exacerbate GHG emissions and climate change; it also holds major potential to mitigate these impacts. Worldwide, the "technical" mitigation potential from agriculture (i.e., the biophysical capacity to mitigate GHG emissions) is estimated to be 5,500-6,000 million tons of CO2-equivalent per year (Mt CO2-eq/yr) by 2030 (Smith et al., 2007).

About $70 \%$ of this mitigation potential lies in developing countries. Sub-Saharan Africa's mitigation potential from agriculture is relatively high, at about $924 \mathrm{Mt} \mathrm{CO} 2-\mathrm{eq} / \mathrm{yr}$ by 2030, compared to $707 \mathrm{Mt} \mathrm{CO} 2-\mathrm{eq} / \mathrm{yr}$ for all of South America and $374 \mathrm{Mt} \mathrm{CO2-eq/yr} \mathrm{for} \mathrm{North} \mathrm{America} \mathrm{.Within} \mathrm{agricultural} \mathrm{systems,} \mathrm{there} \mathrm{are} \mathrm{several} \mathrm{options}$ for mitigating climate change, including both the reduction of existing or potential emissions and the net sequestration of $\mathrm{CO} 2$ to offset emissions elsewhere. The greatest potential mitigation opportunities include (Smith et al., 2007). 
$>$ reduction in $\mathrm{CO2}$ emissions associated with a wide variety of practices, including deforestation for agriculture and oxidation of soil carbon;

$>$ net sequestration of $\mathrm{CO} 2$ in agro ecosystems, including in soils and trees;

$>$ reduction in methane $(\mathrm{CH} 4)$ emissions, which are mostly associated with livestock raising, manure management, and paddy rice production; and

$>$ Reduction in nitrous oxide (N2O) emissions, which are associated with nitrogen cycling and microbial activity in soils of all types.

According to the IPCC, soil carbon sequestration offers by far the most important potential for

Agricultural GHG mitigation, with an estimated $89 \%$ of the total technical potential worldwide. Mitigation of $\mathrm{CH} 4$ emissions and $\mathrm{N} 2 \mathrm{O}$ emissions from soils account for $9 \%$ and $2 \%$, respectively, of the total mitigation potential (with all three gases normalized to units of CO2-eq). These estimates, however, do not include the potential for carbon sequestration or emissions reductions in trees and other aboveground biomass in agricultural landscapes and rural land-use mosaics. With these components added, total mitigation potential from agricultural landscapes remains much larger for $\mathrm{CO} 2$ than for $\mathrm{CH} 4$ or $\mathrm{N} 2 \mathrm{O}$. However, $\mathrm{CH} 4$ is quite important in certain agricultural sectors or components (especially livestock and rice production), while $\mathrm{N} 2 \mathrm{O}$ is a contributing GHG variable in all agricultural sectors, although its dynamics are less well understood (Smith et al., 2007

\subsubsection{Reduced crop and animal yield}

In some sub-regions of Africa, there may be an alarming increase in the risk of hunger due to global warming and decreased crop yield. Decreased yields of major crop cereals in dry and tropical regions of Ethiopia may be one of the outcomes due to climate changes, mainly because of drier conditions. For instance in Kenya, yield in the driest $10 \%$ of years is reduced by $15 \%$ to $60 \%$ from its average (IPCC, 2014). Generally, changes in rainfall, temperature, and air humidity have significant effects on crop yields

\subsubsection{Soil degradation and soil erosion}

Soil erosion means that the upper layer of fertile soil is removed, either by wind, rainwater, or human hands, while soil degradation means that the soil is exhausted and no longer fertile or productive. Soil erosion is a major problem in many parts of the world, and climate changes are likely to exacerbate the problem . Erosion affects crop yields and the quality of agricultural land, and has many undesirable off-farm pollution impacts. Drought, climate changes, and variability exacerbate land degradation in Africa (UNEP, 2009). Especially, the Ethiopian highlands are strongly affected by soil erosion and Moreover, current climate variability is causing natural resource degradation in Ethiopia .

\subsubsection{Increased poverty}

Current climate variability is imposing a significant challenge to Ethiopia by affecting food security, water and energy supply, poverty reduction and sustainable development efforts . Most studies indicate that global mean annual temperature increases of a few degrees or more would prompt food prices to increase due to a slowing in the expansion of global food supply relative to growth in global food demand. Moreover, rainfall variability has been reported to have significant effect on Ethiopia's economy and food production for the last three decades. Furthermore, extreme weather events, such as droughts, floods, or landslides, may cause death to domestic animals Livestock suffering and death often means that the farmer"s wealth is decreased and they lose much of their resources. From 2000 to 2002, the Oromian pastoralists lost nearly two-thirds of their livestock as a result of drought (Difalco, 2011).

\subsection{Conservation Agriculture Practices}

In the past, soil tillage has been associated with increased soil fertility. It has recently been recognized that, in the long term, this process leads to a reduction of soil organic matter. Soil organic matter not only provides nutrients for the crop, but is also a crucial element for the stabilization of soil structure. Therefore, most soils degrade under prolonged intensive arable agriculture. This structural degradation of the soils results in the formation of crusts and compaction, ultimately leading to soil erosion and reduced agricultural productivity. As a result, the conservation agriculture components that are currently being promoted include ( FAO ,2016)

\subsubsection{Crop residue management:}

The success of conservation agriculture in Ethiopia is highly dependent on crop residue management. Crop residues provide protective cover for the soil and increase soil infiltration. Research has shown that when 35 percent of the soil surface is covered with uniformly distributed residues, splash erosion will be reduced by up to 85 percent. Approximately two tons of maize residues per hectare are necessary to obtain 35 percent soil cover, which has been established as the minimum amount required for achieving a substantial reduction in relative soil erosion . In many parts of the country, however, crop residues have traditionally been used for multiple purposes including fuel, building materials and animal feed, which conflict with their use in conservation agriculture. Among these, livestock-related use (feed) is probably the most widespread in the country (Turmel et al., 2015).

\subsubsection{Crop rotation and intercropping}

In a system with reduced mechanical tillage based on mulch cover and biological tillage, alternatives have to be 
developed to control pests and weeds. Practicing crop rotation and intercropping has many advantages, which include reduced risk of pest and weed infestations; better distribution of water and nutrients through the soil profile; exploration for nutrients and water of diverse strata of the soil profile by roots of many different plant species, resulting in a greater use of the available nutrients and water; increased nitrogen fixation through certain plant-soil biota; improved balance of nitrogen, phosphorus and potassium (N-P-K) from both organic and mineral sources; and increased formation of organic matter. Better nutrient management through crop rotation can decrease nitrogen fertilizer use by up to $100 \mathrm{~kg} \mathrm{~N}$ per hectare per year, substantially lowering related greenhouse gas (GHG) emissions (nitrous oxide has a global warming potential 310 times greater than $\mathrm{CO} 2$ ) as well as reducing the costs of production. Reduced synthetic fertilizer use also leads to reduced greenhouse gas emissions from the manufacturing process and transportation (PANW, 2012). However, in most parts of the Ethiopian farming system farmers hardly practice crop rotation and mono-cropping is the dominant cropping system.

\subsubsection{Zero (minimum tillage practices)}

The objective of low tillage (LT) practices (including zero, conservation and minimum

tillage) is to reduce the negative impacts associated with tillage, such as loosening of soils, removal of soil surface cover, destruction of soil structure (which makes it susceptible to soil erosion) and loss of nutrients to the atmosphere through no or minimal disturbance of the soils. The increase in productivity associated with minimal soil disturbance results from increased conservation of soil moisture and increased soil organic matter (SOM) in the top soil (Lal, 2007). The net benefits will be positive from these low tillage technologies if the increase in plant growth parameters is adequate enough to compensate for the negative influence of compacted soils that hinder root development after seed germination, increase weed pressure and reduce water infiltration. Under LT, weed control can, however, be achieved with herbicides.

Another form of conservation tillage is reduced tillage, where there is minimum disturbance of the soil in areas where seeds will be planted, either in rows, planting holes or small basins. This reduces the negative impacts of no tillage and improves root growth and penetration, and water infiltration, while maintaining surface mulch and slowing down decomposition of organic residues. Reduced tillage can be achieved through either ripping or small planting basins. Under ripping, a ripper is used to break clogs along the planting rows. Small planting basins that collect and store rain water are made, measuring $30-\mathrm{cm}$ long and $20 \mathrm{~cm}$ deep at $70 \mathrm{~cm}$ spacing along the planting rows and $90 \mathrm{~cm}$ apart between rows to form rows of small basins. Seeding and fertilizer application is done in each basin. The spacing may depend on the requirements of the crops to be planted. Eight to ten maize or 10-20 bean seeds can be planted in a basin. Adoption of conservation agriculture was, however, reported to be low mainly due to lack of training, poverty and land ownership issues (Lal, 2007).

\subsubsection{Crop diversification and cropland management}

One of the major sources of greenhouse gases in the atmosphere is the application of fertilizers to agricultural land. Nitrous oxide (N2O) is emitted when nitrogen in synthetic fertilizers is added to the soil. The nitrogen stimulates microbes in the soil to produce more nitrous oxide, thereby increasing greenhouse gas emissions. Nitrous oxide is the third most important greenhouse gas, after carbon dioxide and methane, but has up to 300 times more warming effects as compared to carbon dioxide. The increased use of nitrogen-based fertilizers has resulted in the increase in nitrous oxide emissions in recent years. African production systems, however, are not responsible for the increase since properly synchronizing the timing of fertilizer application will result in the release $\mathrm{N} 2 \mathrm{O}$ only after meeting the crops requirements. In addition, small-scale farmers across the region have been applying fertilizers at rates lower than recommended (Kassie al., 2008). African farmers could, however, still contribute to the mitigation of climate change through the adoption of technologies that reduce emissions or absorb green house gases. The crop management technologies include all technologies that utilize crop diversity and their unique characteristics that may provide synergies in crop production. Across the region, there is a general shift away from mono-cropping among small scale farmers.

\subsection{5 . Cover crops}

Cover crops help to loosen up the soil, conserve moisture, reduce soil erosion, reduce labour, and increase nitrogen in the soil. With increasing temperature and dwindling rainfall amounts across the countries, the cover crops support food crop production in areas that are normally difficult to farm on. Leguminous crops (either grown together with food crops or solely as a fallow crop) are the most common cover crops and include Lablab - Lablab purpureus(L.) or Dolichos lablab (L.),Velvet bean (Mucuna pruriens), Cowpea (Vignaun guiculata) and common types of beans. Crotalaria species (Crotalaria ochroleucaand Crotalaria grahamiana), Mucunapruriensand Canavaliaensiformis have been successful in Kenya and Uganda, with significant increase in maize yield following sole cropping of the fallow crops. The increase in production from using cover crops is so high that some scientists believe that leguminous crops could entirely substitute inorganic nitrogen fertilizer at the low average of the farmers in the region. Indeed of the nitrogen derived through Biological Nitrogen Fixation (BNF), about 43 percent in Mucunacontributes the nitrogen requirements at moderate levels of output under favorable conditions (Giller $e t$ al., 2009). Other crops used as cover crops, either at planting or during fallow periods, include Sesbaniasesban(L), Leucaenaleucocephala (cv Cunningham) and Cajanuscajan (Pigeon pea). The capacity of the leguminous cover 
crops rests in its high affinity for association with several Rhizobia in the soil causing formation of numerous and large nodules in the plant roots to fix nitrogen. The challenges in using cover crops are that it may be difficult to achieve net nitrogen fixation, especially if fixed nitrogen is less than what is required by the succeeding crops. The adoption of cover crops is also affected when the cover crops cannot be used as food or fodder crop, or where environmental factors affect the growth of the cover crops during the off-seasons. When crop growth is not well synchronized with the release of nitrogen by the cover crop, the nitrogen fixed is lost through leaching or denitrification .

\subsection{Environmental Impacts of Conservation Agriculture}

\subsubsection{Soil fertility}

In terms of soil fertility, the improved soil structure resulting from conservation agriculture enhances aeration and other conditions required for efficient nutrient cycling. Soil organic matter has been found to increase significantly over time in conservation agriculture systems, primarily due to the introduction of additional organic matter as crop residues or mulch and to the reduction or elimination of tillage, which tends to accelerate the oxidation of soil organic matter (Kassam et al., 2009). Zero tillage systems are also associated with increased levels of available phosphorus in the upper soil layer due largely to the role of biological processes in phosphorus cycling.

\subsubsection{Water management}

Conservation agriculture has been found to have beneficial effects on water management and water-use efficiency. With an increase in soil organic matter and root density under conservation agriculture, water infiltration and water holding capacity are improved, making water more available throughout the farming cycle. Kassam et al.(2009) reported that for each percent increase in soil organic matter, an additional $150 \mathrm{~m} / \mathrm{ha}$ of water can be stored in the soil. Surface mulches and improved soil pore structure also increase infiltration and absorption capacity, while reducing evaporation. These benefits help reduce the risk of erosion and flooding during heavy rains, contribute to aquifer recharge and make more water available for crops (Sintayehu, 2011).

\subsubsection{Food security}

Sustained and stable food production generated by conservation agriculture systems can significantly improve the food security and nutritional status of vulnerable households and communities. Conservation agriculture can help stabilize yields in the face of climate shocks such as droughts by reducing evapotranspiration and regulating soil temperatures as well as supporting the management of pests and diseases in crop production if appropriate crop rotations and combinations are used. These benefits are especially important for poor and vulnerable smallholder farming households (Hobbs et al., 2008).

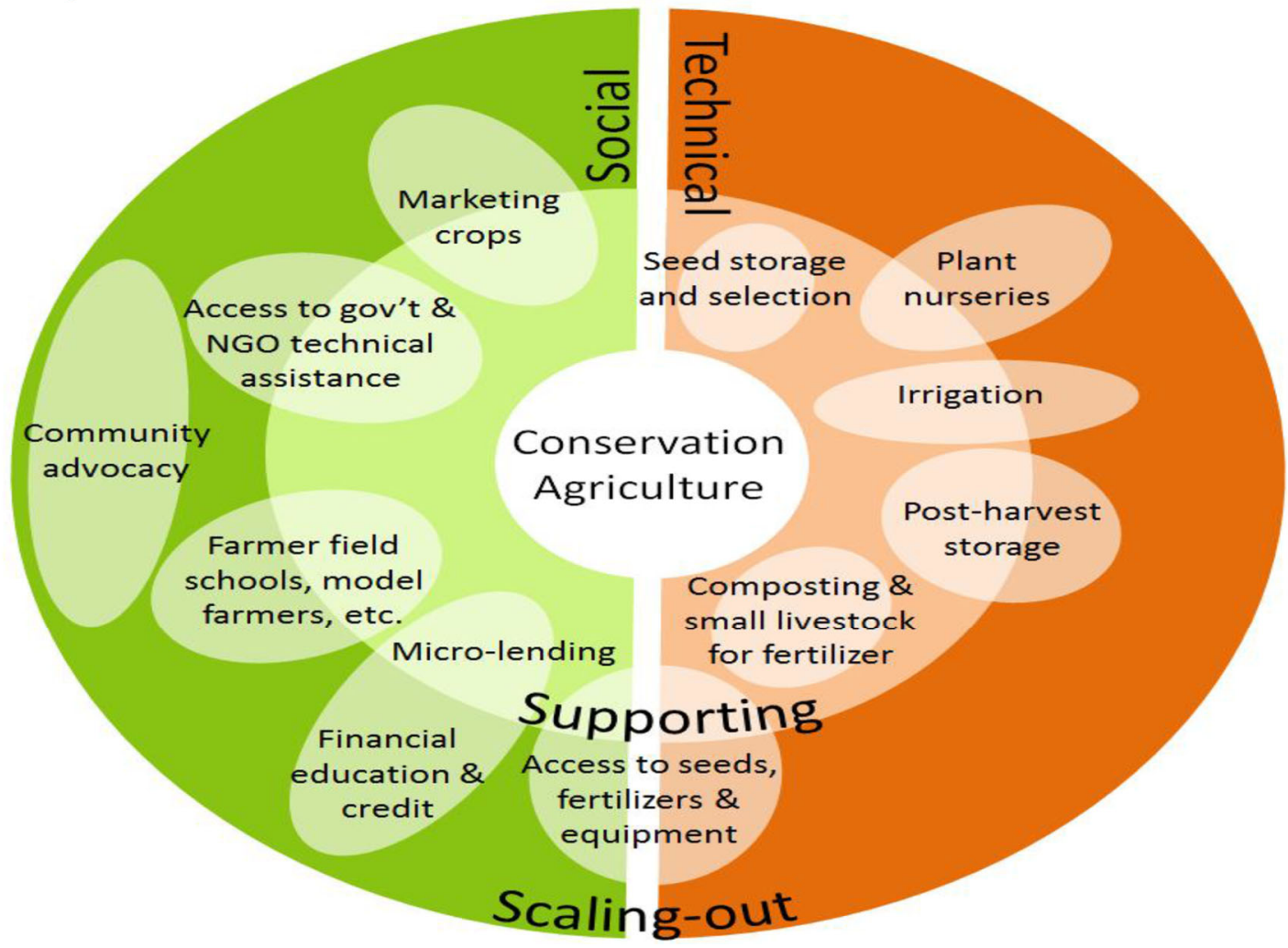

Figure 1. "Expanding orbits" of practices, activities, and institutions that can enhance the scale and effectiveness of conservation agriculture as a sustainable livelihood strategy. 


\subsection{Challenges to Conservation Agriculture Promotion}

Despite conservation agriculture having been introduced in Ethiopia over 16 years ago, adoption of thepractice remains low and has not progressed as fast is it could have. Some of the challenges in the promotion and adoption of conservation agriculture in the country are listed below (FAO, 2016)

\subsubsection{Inadequate integration of conservation agriculture}

Conservation agriculture promotion in Ethiopia has been implemented mainly by NGOs and private sector organizations, while emphasis given by responsible government institutions like the Ministry of Agriculture, in particular the Agricultural Extension Directorate, has not been sufficient in the past. In particular, conservation agriculture is not adequately integrated into the existing agricultural extension delivery system of the MoA. In addition, since conservation agriculture has mostly been implemented by NGOs, there has not been adequate government

Follow-up, support and appropriate monitoring to ensure sustainability and wide adoption of the practice (FAO, 2016).

\subsubsection{Open grazing system}

Open grazing is a challenge not only to conservation agriculture in Ethiopia, but also to overall agricultural development and environmental sustainability. Open grazing results in the removal of crop residues from conservation agriculture fields and causes soil compaction that results in hard pans and difficulty in planting using simple planters or simple rippers that are suitable for smallholders. If livestock are accustomed to feeding on crop residues, a conflict of interest can be created when crop residues need to be kept for mulching. Crop-livestock conflicts need to be considered when promoting conservation agriculture (FAO, 2016).

\subsubsection{Lack of alternative energy sources}

In most parts of rural Ethiopia, crop residue is not only used as a livestock feed, but also as a fuel wood for cooking purposes. Most farmers do not have woodlots and hence crop residue is one of the main sources of fuel wood for cooking. In promoting conservation agriculture there is a need to consider mechanisms to support farmers to access alternative energy sources (FAO, 2016).

\subsubsection{High input prices}

Prices for high-quality inputs such as herbicides, fertilizer, improved seeds and implements have been steadily increasing in Ethiopia and at times the prices are beyond the capacity of many smallholder farmers. One example is non-selective herbicides which, according to farmers, have more than doubled in price within three years. A means of supporting smallholder farmers to access inputs so that they can undertake conservation agriculture and other CSA practices is needed(FAO,2016)

\subsubsection{Lack of availability of required inputs and equipment:}

It has frequently been reported that inputs such as non-selective glyphosate-based herbicides are difficult to access and those that are available are not effective, thus making it difficult for farmers to adopt conservation agriculture owing to weed problems. The same applies to other inputs required for practicing conservation agriculture such as seeds for rotation crops as well as conservation agriculture implements such as rippers and direct seeders, which are not available at times or, when available, are of poor quality (FAO,2016)

\subsubsection{Environment, biodiversity and soils:}

Conservation agriculture has a significant impact in reducing soil erosion through increased rainwater infiltration and buildup of soil organic matter for increased soil moisture storage. Conservation agriculture can improve biodiversity at farm and community level and support improved ecosystem services such as water and nutrient cycling. It can also support flood control through improved water infiltration in agricultural fields (FAO, 2016).

\section{SUMMARY}

Smallholders in Ethiopia face widespread problems related to inappropriate cultivation, overgrazing and deforestation, resulting in soil erosion and soil fertility decline, water scarcity, lack of pasture and livestock feed, and fuel wood crisis. This vicious cycles requiring urgent action and different approaches in the dry lands and highland areas adapting to climate change Through land and Water management. Increasing weather variability and climate change are contributing to land and natural resource degradation by exposing soils to extreme conditions and straining the capacity of existing land management practices to maintain resource quality. Results include degradation of vegetation cover and loss of biodiversity, soil erosion, depletion of organic matter, reduced rainwater infiltration and water holding capacity of the soil and loss of productivity and effects on wider ecological functions. so by considering the climate change as national and global condition it is a time to taking action through different alternatives. Among the options conservation agriculture system is one of non-substitutable option among others due to its smartness with climate change by improving soil fertility, water management and food security.

\section{REFERENCES}

Canadell, J.G., M.R. Raupach, and R.A. Houghton. 2009. Anthropogenic CO2 emissions in Africa. Biogeo sciences 6: 463-468 
Conway, D. and Schipper, E.L.F. (2011). Adaptation toclimate change in Africa: Challenges and opportunitiesidentified from Ethiopia. Global Environmental Change,21 (2011) 227-237.

DFID (2011) Strategic Climate Institutions Programme,

Di Falco, S., Marcella, V. \& Mahmud, Y. 2011. Does adaptation to climate change provide food security? A microperspective from Ethiopia.American Journal of Agricultural Economics, 93(3), 825-842.

FAO. 2010. Chair's summary of The Hague Conference on Agriculture, Food Security and Climate Change. Accessible at: 074bd320c6c51936e3f40ee190975f011.pdf [Read 28.08.16].

FAO. 2013. Climate-Smart Agriculture Sourcebook. FAO, Rome.

FAO. 2016. Ethiopia Climate-Smart Agriculture Scoping Study. By Jirata, M., Grey, S. \&Kilawe, E. FAO, Addis Ababa.

Giller, K.E., Witter, E., Corbeels, M. \&Tittonell, P. 2009. Conservation agriculture and smallholder farming in Africa: the heretics' view. Field Crops Research, 114 (1), 23-34.

Hobbs, P. R., Sayre, K. \& Gupta, R. 2008. The role of conservation agriculture in sustainable agriculture.Philosophical Transactions: Biological Sciences, 363(1491), 543-555.

IPCC, 2014: Climate Change 2014: Synthesis Report. Contribution of Working Groups I, II and III to the Fifth Assessment Report of the Intergovernmental Panel on Climate Change [Core Writing Team, R.K. Pachauri and L.A. Meyer (eds.)]. The Intergovernmental Panel on Climate Change, Geneva.

Kassam, A., T. Friedrich, F. Shaxson, and J. Pretty. 2009. The spread of conservation agriculture:justification, sustainability and uptake. International Journal of Agricultural Sustainability 7: 292-320.

Kassie, M., Zikhali, P., Pender, J. \&Köhlin, G. 2011b.Sustainable agricultural practises and agricultural productivity in Ethiopia. Does agroecology matter? Environment for Development, Discussion Paper Series.

Lal, R. 2007. Constraints to adopting no-till farming in developing countries.Soil \& Tillage Research, 94, 1-3.

Lipper, L., Thornton, P., Campbell, B.M., Baedeker, T., Braimoh, A., Bwalya, M., Caron, P., Cattaneo, A., Garrity, D., Henry, K., Hottle, R., Jakson, L., Jarvis, A., Kossam, A., Mann, W., McCarthy, N., Meybeck, A., Neufeldt, H., Remington, T., ThiSen, P., Sessa, R., Shula, R., Tibu, A. \&Torquebiau, E.F. 2014. Climate-smart agriculture for food security.Nature Climate Change, 4, 1068-1072.

Lobell, D.B., Schlenker, W. \& Costa-Roberts, J. 2011.Climate trends and global crop production since 1980.Science, 333, 616-620.

McKenzie, F.C. \& Williams, J. 2015. Sustainable food production: constraints, challenges and choices by 2050. Food Security.7(2), 221-233. 103 Meteorological Agency

Neufeldt, H., Jahn, M., Campbell, B.M., Beddington, J.R., DeClerck, F., De Pinto, A., Gulledge, J., Hellin, J., Herrero, M., Jarvis, A., LeZaks, D., Meinke, H., Rosenstock, T., Scholes, M., Scholes, R., Vermeulen, S., Wollenberg, E. \&Zougmoré, R. 2013. Beyond climate-smart agriculture: toward safe operating spaces for global food systems. Agriculture \& Food Security, 2 (12), 1-6.

PANW. 2012. Crop rotation benefiting farmers, the environment

Sintayehu, W. 2011. Presentation made at the National Policy Workshop on Climate Change Adaptation and Mitigation. Climate Change Forum and CCAFS, 2011.

Smith, P., D. Martino, Z. Cai, D. Gwary, H. Janzen, Rice, B. Scholes, O. and Sirotenko. 2007. Agriculture. Pages 497-540 in Metz, B., O.R. Davidson,

Turmel, M., Speratti, A., Baudron, F., Verhulst, N., \&Govaerts, B. 2015. Crop residue management and soil health: A systems analysis. Agricultural Systems, 134, 6-16. UK and New York.

UNEP. 2009. The environmental food crisis: The environment's role in averting future food crises. United Nations Environment Programme, Nairobi. 